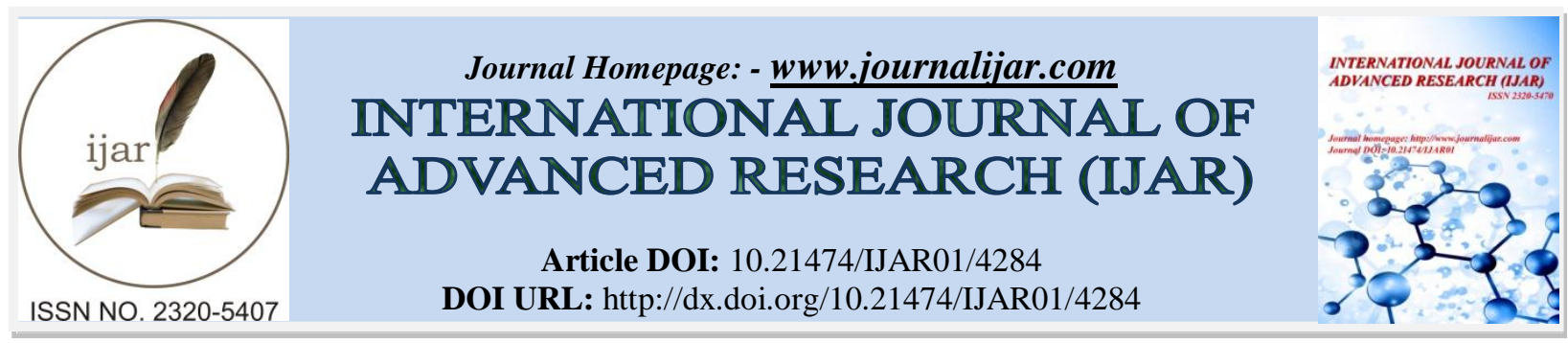

RESEARCH ARTICLE

\title{
A STEADY FLOW OF BLOOD THROUGH A STENOSED ARTERY WITH A BALLOON-CATHETER TECHNIQUE.
}

\author{
Rupesh K. Srivastav ${ }^{1}$, Manisha Gupta ${ }^{2}$ and Poonam Sinha ${ }^{3}$. \\ 1. Department of Mathematics, AIMT, Lucknow-226026, India. \\ 2. Math Section-IT Department, Higher College of Technology, Sultanate of Oman. \\ 3. Department of Mathematics, S.M.S.Govt. Science College, Gwalior-474001, India.
}

\section{Manuscript Info}

Manuscript History

Received: 28 March 2017

Final Accepted: 30 April 2017

Published: May 2017

Key words:-

Stenosis, Catheter, Impedance, Shear stress.

\section{Abstract}

In the present paper, an analysis of blood flow through a stenosed artery with a balloon based catheter technique has been carried out where the blood is treated as Newtonian fluid. The governing equation of motion is solved and closed form expressions for dimensionless resistance to flow, the wall shear stress and the shearing stress on the wall at maximum height of the stenosis are obtained. The behavior of these flow characteristics in this constricted annular region has been discussed. Their variations with different flow parameters are plotted in figures.

Copy Right, IJAR, 2017,. All rights reserved.

\section{Introduction:-}

Blood is a marvelous fluid which nurtures the life. Blood flow in artery has some important aspects due to engineering as well as medical application point of view. For over a couple of centuries, the theoretical and experimental studies of blood flow through the circulatory system of living mammals, has been the subject of scientific research. Mathematical modeling of blood flow has been subject subject of modifications in order to account for the new evidences uncovered through the improved initial experimental observation.

The frequently occurring cardiovascular disease, stenosis, is defined as a partial occlusion of the blood vessels due to accumulation of cholesterol, fats and the abnormal growth of tissue. Once the constriction is formed, the blood flow is significantly altered and fluid dynamical factor play important roles as stenosis continues to enlarge leading to development of diseases such as heart attack and stroke. Young and Tsai (1973) discussed some characteristics of flow of blood in stenosed arteries. Quite a good number of analytical studies pertaining to the blood flow through stenosed arteries have been carried out by Young and Tsai (1973); By assuming the artery to be circulatory cylindrical in shape, Mishra and Panda (2005) studied the flow of blood in stenosed artery for the Casson fluid; Srivastava et al. (2010), Ponalagusamy (2011); Riahi et al (2012); Medhavi et al. (2012), Ledesma et al. (2013), Venkatesan et al. (2013), Akbar et al.(2014), Srivastav at al. (2014a, b); Hazarika et al. (2014); Srivastav RK (2014, 2015, 2017); and many others; in order to analyze the arterial constriction on the flow characteristics of blood. In large vessels, which include large cavities such as the ventricles and atria inside the myocardium as well as the large arteries and veins, the blood essentially behaves as a Newtonian fluid (Caro et al., 1978) and non-Newtonian effects which are basically induced at low shear rates die out (Perktold et al., 1999). No single model, Newtonian or nonNewtonian, can capture all the features of the blood complexities (Yilmaz et al., 2008) and hence different models are used to represent different characteristics of the blood rheology. 
Catheters are of extensive use in modern medicine. Catheters are also being used in diagnostic technique, e.g. X-ray angiography as well as in treatment procedures of various arterial diseases. An inserted catheter in an artery will increase the impedance and will modify the pressure distribution and alter the flow field. A review of most of the experimental and theoretical investigation on artery catheterization has been presented by Srivastava at al. (2008). Dash et al. (1996) considered the steady and pulsatile flow of Casson fluid in a narrow artery when catheter is inserted into it and estimated the increase in frictional resistance in the artery due to catheterization. In ballooncatheter technique, a catheter with an inflatable balloon at its tip which is used during a catheterization procedure to enlarge a narrow opening or passage within the artery. The catheter is carefully guided to the location at which stenosis occurs in coronary arteries and then balloon is then inflated to fracture the fatty deposits and widen the narrowed portion, McMahon et al. (1971), Gabe (1972). Gunj et al. (1985); Anderson et al. (1986) and Wilson et al. (1988) have studied the measurement of translational pressure gradient during angioplasty.

With the above discussion in mind, the goal of this investigation is to study the effect of a balloon- catheter technique on various physiologically important flow characteristics i.e. impedance, wall shear stress distribution in stenotic region and shear stress at stenosis throat, as on flow patterns in artery with overlapping stenosis through a mathematical model.

\section{Formulation Of The Problem:-}

Consider the axisymmetric flow of blood through the gap between an artery of circular cross section with an overlapping stenosis specified at the position as shown in Figure-1 and a catheter having a balloon. The geometry of arterial wall with the overlapping stenosis and balloon model are defined by functions $R(z)$ and $R_{c}(z)$ respectively and described as

$$
\begin{aligned}
& \frac{\mathrm{R}(\mathrm{z})}{\mathrm{R}_{0}}=\left\{\begin{array}{l}
1-\frac{3}{2} \frac{\delta}{R_{0} L_{0}^{4}}\left[11(z-d) L_{0}^{3}-47(z-d)^{2} L_{0}^{2}+72(z-d)^{3} L_{0}-36(z-d)^{4}\right] \\
1, \quad \text { otherwise }
\end{array}\right. \\
& \frac{\mathrm{R}_{\mathrm{c}}(\mathrm{z})}{\mathrm{R}_{0}}=\left\{\begin{array}{l}
k+\frac{\delta_{0}}{R_{0}} \exp \left\{-\pi^{2}\left(z-z_{d}-0.5\right)^{2}\right\} \\
k, \text { otherwise }
\end{array}\right.
\end{aligned}
$$

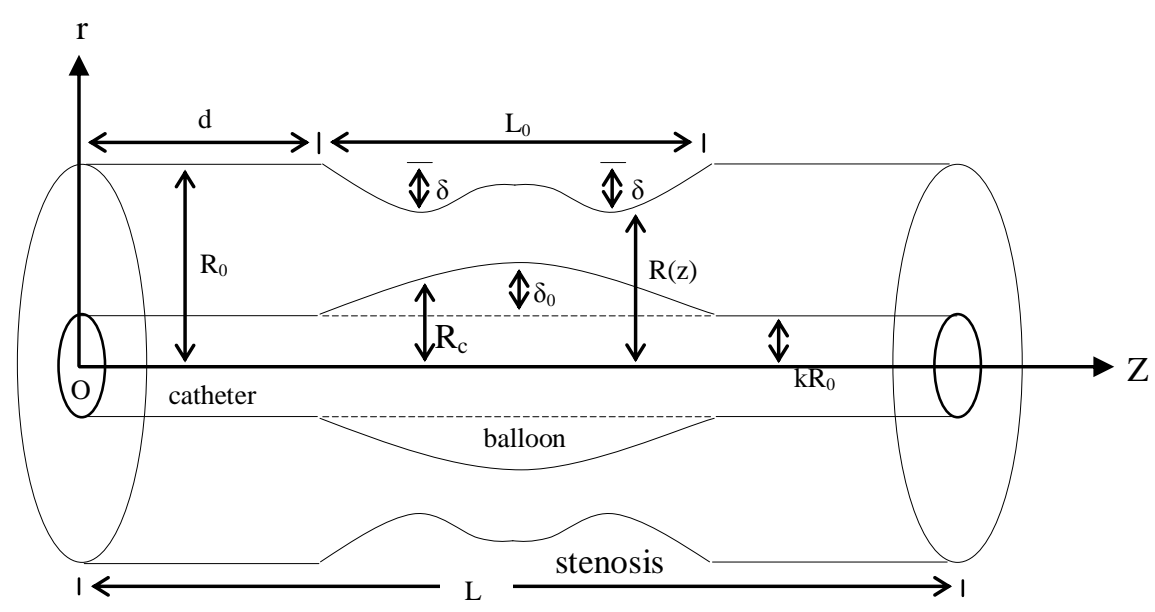

Figure 1:- The geometry of overlapping stenosis in inserted catheterized artery having a balloon

where $\mathrm{R}_{0}$ are the radius of the tube without stenosis, $\mathrm{L}_{0}$ is the stenosis length, $\mathrm{d}$ indicates stenosis location, $\delta$ is the critical height of the stenosis into the lumen, appears at the locations: $z=\mathrm{d}+\mathrm{L}_{0} / 6$ and $\mathrm{d}+5 \mathrm{~L}_{0} / 6, z$ being the axial coordinate. The maximum height attained by the balloon at $\mathrm{z}=\mathrm{d}+\mathrm{L}_{0} / 2$ is $\delta_{0}$ and $\mathrm{kR}_{0}$ is the radius of the inner tube which keeps the balloon in position, $\mathrm{k}<<1$, and $\mathrm{z}_{\mathrm{d}}$ represents the axial displacement of balloon. 
Blood is assumed to be represented by a Newtonian fluid. Considering a steady, the axisymmetric, laminar, fully developed one-dimensional flow of blood in an artery, the governing equation in a mild stenosis case, under the conditions (Young, 1968; Srivastava et al. 2010): $\delta / \mathrm{R}_{0} \ll 1, \mathrm{R}_{\mathrm{e}}\left(2 \delta / \mathrm{L}_{0}\right) \ll 1$ and $2 \mathrm{R}_{0} / L_{0} \sim O(1)$, may be stated as

$$
\frac{\mathrm{dp}}{\mathrm{dz}}=\frac{\mu}{\mathrm{r}} \frac{\partial}{\partial \mathrm{r}}\left(\mathrm{r} \frac{\partial}{\partial \mathrm{r}}\right) \mathrm{u}
$$

where $(r, z)$ are cylindrical polar coordinates system with $z$ measured along the tube axis and $r$ measured normal to the axis of the tube, $R_{e}$ is the tube Reynolds number, $p$ is the pressure and $(u, \mu)$ is the fluid (velocity, viscosity).

The boundary conditions are

$$
\begin{aligned}
& \mathrm{u}=0 \text { at } \mathrm{r}=\mathrm{R}, \\
& \mathrm{u}=0 \text { at } \mathrm{r}=\mathrm{R}_{\mathrm{c}},
\end{aligned}
$$

Conditions (4) and (5) are the standard no slip conditions at the artery and balloon-catheter walls, respectively.

\section{Analysis:-}

The expression for the velocity obtained as the solution of equation (3) subject to the boundary conditions (4) and (5), is given as

$$
\mathrm{u}=-\frac{\mathrm{R}_{0}^{2}}{4 \mu} \frac{\mathrm{dp}}{\mathrm{dz}}\left[\left(\frac{\mathrm{R}}{\mathrm{R}_{0}}\right)^{2}-\left(\frac{\mathrm{r}}{\mathrm{R}_{0}}\right)^{2}+\frac{\left\{\left(\mathrm{R} / \mathrm{R}_{0}\right)^{2}-\left(\mathrm{R}_{\mathrm{c}} / \mathrm{R}_{0}\right)^{2}\right\}}{\log \left(\mathrm{R} / \mathrm{R}_{\mathrm{c}}\right)} \log \left(\frac{\mathrm{r}}{\mathrm{R}}\right)\right],
$$

The flow flux, $\mathrm{Q}$ is thus calculated as

$$
\begin{aligned}
\mathrm{Q} & =2 \pi \int_{\mathrm{R}_{\mathrm{c}}}^{\mathrm{R}} \mathrm{r} \mathrm{u} d \mathrm{r} \\
& =-\frac{\pi R_{0}^{4}\left\{\left(\mathrm{R} / \mathrm{R}_{0}\right)^{2}-\left(\mathrm{R}_{\mathrm{c}} / \mathrm{R}_{0}\right)^{2}\right\}}{8 \mu} \frac{d p}{d z}\left[\left(\frac{\mathrm{R}}{\mathrm{R}_{0}}\right)^{2}+\left(\frac{\mathrm{R}_{\mathrm{c}}}{R_{0}}\right)^{2}-\frac{\left\{\left(\mathrm{R} / \mathrm{R}_{0}\right)^{2}-\left(\mathrm{R}_{\mathrm{c}} / \mathrm{R}_{0}\right)^{2}\right\}}{\log \left(\mathrm{R} / \mathrm{R}_{\mathrm{c}}\right)}\right],
\end{aligned}
$$

From equation (7), one now obtains

$$
-\frac{\mathrm{dp}}{\mathrm{dz}}=\frac{8 \mu \mathrm{Q}}{\pi \mathrm{R}_{0}^{4}} \varphi(\mathrm{z})
$$

with $\varphi(\mathrm{z})=1 / \mathrm{F}(\mathrm{z}), \mathrm{F}(\mathrm{z})=\left\{\left(\frac{\mathrm{R}}{\mathrm{R}_{0}}\right)^{2}-\left(\frac{\mathrm{R}_{\mathrm{c}}}{R_{0}}\right)^{2}\right\}\left[\left(\frac{\mathrm{R}}{\mathrm{R}_{0}}\right)^{2}+\left(\frac{\mathrm{R}_{\mathrm{c}}}{R_{0}}\right)^{2}-\frac{\left\{\left(\mathrm{R} / \mathrm{R}_{0}\right)^{2}-\left(\mathrm{R}_{\mathrm{c}} / \mathrm{R}_{0}\right)^{2}\right\}}{\log \left(\mathrm{R}_{\mathrm{R}}\right)}\right]$.

The pressure drop, $\Delta \mathrm{p}(=\mathrm{p}$ at $\mathrm{z}=0,-\mathrm{p}$ at $\mathrm{z}=\mathrm{L})$ across the stenosis in the tube of length, $\mathrm{L}$ is obtained as

$$
\begin{aligned}
& \Delta \mathrm{p}=\int_{0}^{\mathrm{L}}\left(-\frac{\mathrm{dp}}{\mathrm{d} z}\right) \mathrm{dz}, \\
& \Delta \mathrm{p}=\frac{8 \mu \mathrm{Q}}{\pi \mathrm{R}_{0}^{4}} \psi,
\end{aligned}
$$

where $\psi=\int_{0}^{\mathrm{d}}[\varphi(\mathrm{z})]_{\mathrm{R} / \mathrm{R}_{0}=1, \mathrm{R}_{\mathrm{C}} / \mathrm{R}_{0}=k} \mathrm{dz}+\int_{\mathrm{d}}^{\mathrm{d}+\mathrm{L}_{0}}[\varphi(\mathrm{z})]_{\mathrm{R} / \mathrm{R}_{0}}$ from (1), $R_{C} / \mathrm{R}_{0}$ from (2) $\mathrm{dz}+\int_{\mathrm{d}+\mathrm{L}_{0}}^{\mathrm{L}}[\varphi(\mathrm{z})]_{\mathrm{R} / \mathrm{R}_{0}=1, \mathrm{R}_{\mathrm{C}} / \mathrm{R}_{0}=k} \mathrm{dz}$,

Using the definitions from the published literature, Srivastava et al. (2010), the expressions for the impedance (flow resistance), $\bar{\lambda}$ the wall shear stress in the stenotic region, $\bar{\tau}_{w}$ and the shear stress at stenosis throat, $\bar{\tau}_{s}$ are given as

$$
\bar{\lambda}=\frac{\Delta p}{Q}, \bar{\tau}_{w}=-\frac{R}{2}\left(\frac{d p}{d z}\right), \bar{\tau}_{\mathrm{s}}=\left[\bar{\tau}_{w}\right]_{R / R_{0}=1-\delta / R_{0}},
$$


Following now the reports of Young (1968); the expressions for impedance, $\lambda$, the wall shear stress, $\tau_{w}$, and shear stress at stenosis throat, $\tau_{s}$, in their non-dimensional form are derived as

$$
\begin{aligned}
\lambda & =\frac{\left(1-L_{0} / L\right)}{\eta}+\frac{1}{\mathrm{~L}} \int_{\mathrm{d}}^{\mathrm{d}+\mathrm{L}_{0}}[\varphi(\mathrm{z})]_{\mathrm{R} / \mathrm{R}_{0} \text { from (1), } R_{c} / \mathrm{R}_{0} \text { from (2) }} \mathrm{dz}, \\
\tau_{\mathrm{w}} & =\frac{\left(R / R_{0}\right)}{\left\{\left(\frac{R}{R_{0}}\right)^{2}-\left(\frac{\mathrm{R}_{\mathrm{c}}}{R_{0}}\right)^{2}\right\}\left[\left(\frac{R}{R_{0}}\right)^{2}+\left(\frac{\mathrm{R}_{\mathrm{c}}}{R_{0}}\right)^{2}-\left\{\left(\frac{R}{R_{0}}\right)^{2}-\left(\frac{\mathrm{R}_{\mathrm{c}}}{R_{0}}\right)^{2}\right\} / \log \frac{R}{R_{c}}\right]}, \\
\tau_{\mathrm{s}} & =\left[\tau_{w}\right]_{R / R_{0}=1-\delta_{1} / R_{0}},
\end{aligned}
$$

where $\eta=\left(1-k^{2}\right)\left\{1+k^{2}+\left(1-k^{2}\right) / \log k\right\}, \lambda=\bar{\lambda} / \lambda_{0},\left(\tau_{\mathrm{w}}, \tau_{\mathrm{s}}\right)=\left(\bar{\tau}_{\mathrm{w}}, \bar{\tau}_{\mathrm{s}}\right) / \tau_{0}$, and $\lambda_{0}$ and $\tau_{0}$ are the flow resistance and shear stress, respectively for a Newtonian fluid in a normal artery (no stenosis), and are given by

$$
\lambda_{0}=\frac{8 \mu L}{\pi R_{0}^{4}}, \tau_{0}=\frac{4 \mu Q}{\pi R_{0}^{3}}
$$

\section{Numerical Results And Discussion:-}

Computer codes are developed to evaluate the analytic results in non-dimensional form obtained for the impedance (resistance to flow), the wall shear stress distribution in stenotic region, shear stress at stenosis throat, in order to be able to discuss the result obtained in Eqs. (10), (11) and (12) quantitatively and , by using the following experimental data: $\mathrm{d}(\mathrm{cm})=0 ; \mathrm{L}=\mathrm{L}_{0}=1 \mathrm{~cm} ; \delta / \mathrm{R}_{0}$ (non-dimensional stenosis height) $=0,0.05,0.10,0.15,0.20 ; \mathrm{k}$ $=0.001,0.01,0.1, \delta_{0} / R_{0}$ (non-dimensional balloon height) $=0,0.05,0.10,0.15,0.20 ; \mathrm{z}_{\mathrm{d}}=0,0.10,0.2,0.4,0.6$ and presented graphically.

The impedance is an important factor which may play a vital role in the diagnosis and treatment of heart attack and stroke. The variations of impedance with different parameters have been discussed in Figures 2-4. The insertion of balloon- catheter system in stenosed artery has significant effect on the flow characteristics, impedance in lumen of artery. Figure-2 illustrate that resistance to flow (impedance), $\lambda$, increases with stenosis height, $\delta / R_{0}$, for given height of balloon and for different catheter size. For stenosis height, $\delta / R_{0}=0.10$, the resistance to flow increases due to balloon of height, $\delta_{0} / R_{0}=0.1$ is about $32.44 \%, 24.77 \%$ and $20.48 \%$ approximately over that of stenosed catheterized artery without balloon for $\mathrm{k}=0.001,0.01$ and 0.1 .

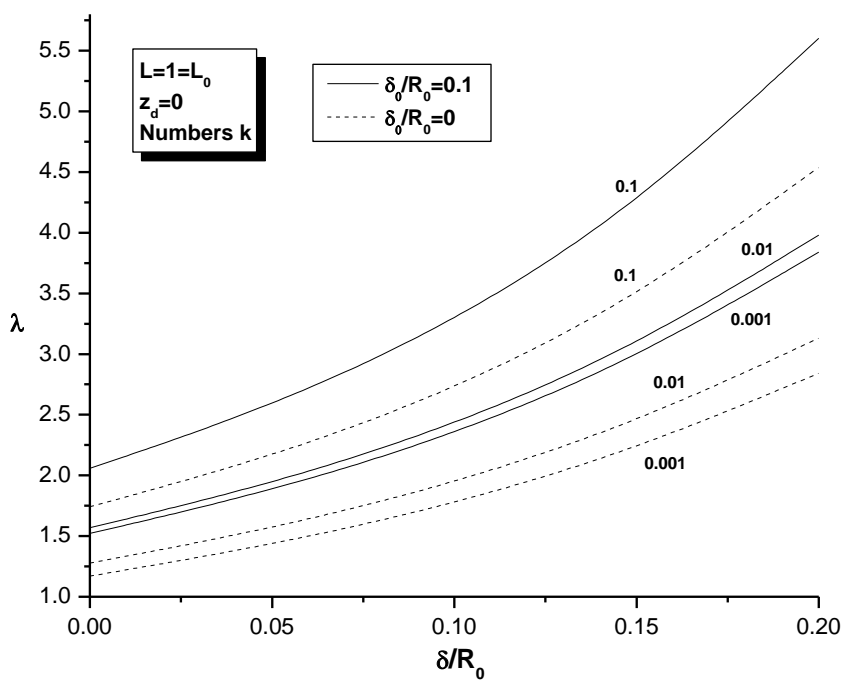

Figure 2: Variation of impedance, $\lambda$ with stenosis height, $\delta / \mathbf{R}_{0}$ for different catheter size, $k$. 


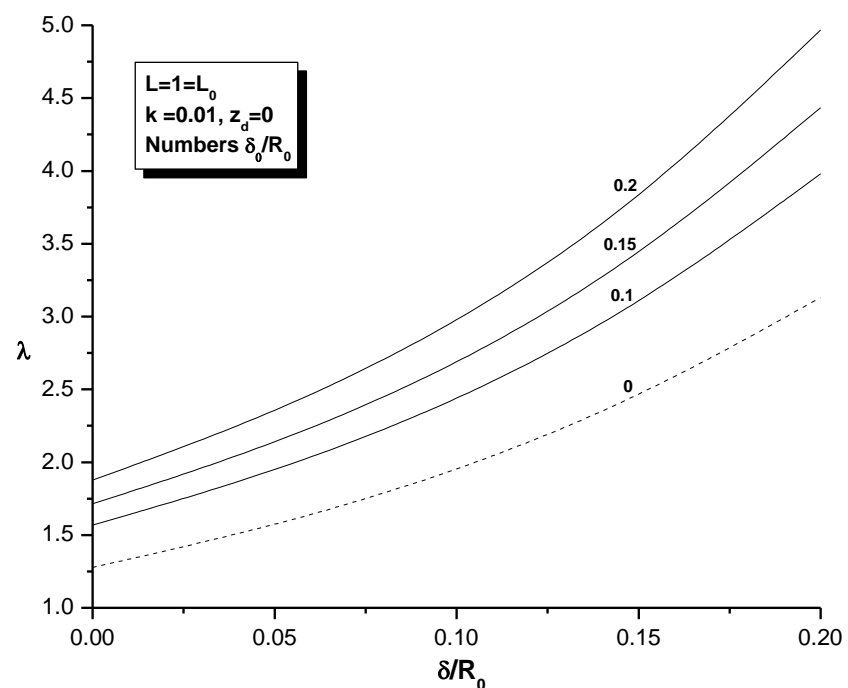

Figure 3: Variation of impedance, $\lambda$ with stenosis height, $\delta / R_{0}$ for different height of balloon, $\delta_{0} / R_{0}$.

Figure-3 illustrate that resistance to flow, $\lambda$, increases with stenosis height for given catheter size. For $\varepsilon=0.01$, the resistance to flow, $\lambda$, increases due to balloon of height, $\delta_{0} / \mathrm{R}_{0}=0.1,0.15,0.20$ is about $24.77 \%, 37.51 \%$ and $52.22 \%$ approximately over that of stenosed catheterized artery for stenosis height, $\delta / \mathrm{R}_{0}=0.10$.

It has been observed that for any given set of parameters, the flow resistance, $\lambda$, decreases with the increasing values of the axial displacement of balloon, $\mathrm{z}_{\mathrm{d}}$ (Figure-4).

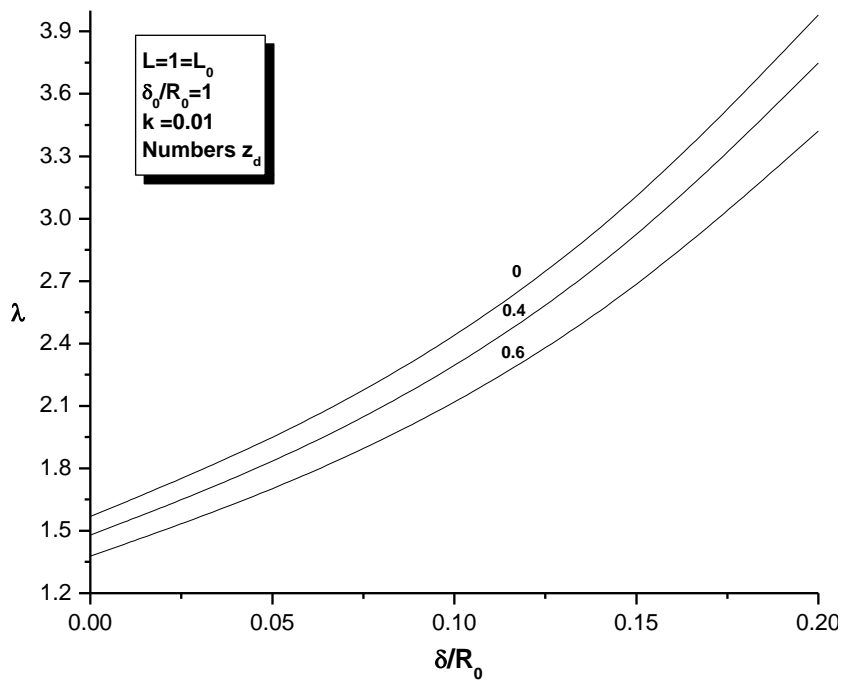

Figure 4: Variation of impedance, $\lambda$ with stenosis height, $\delta / \mathbf{R}_{0}$ for different axial displacement of balloon, $\mathbf{z}_{\mathrm{d}}$. 


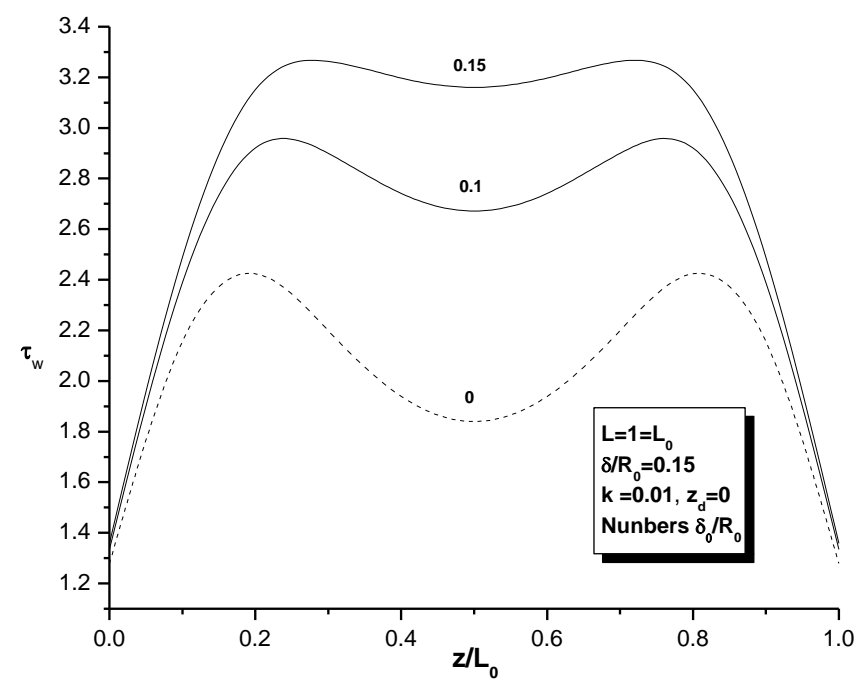

Figure 5: Wall shear stress distribution, $\tau_{w}$ in stenotic region for different height of balloon, $\delta_{0} / R_{0}$.

The wall shear stress is an important diagnostic factor to understand the development of arterial disease. The variations of wall shear stress with different parameter have been discussed in Figures 5-7. It is noticed that as height of stenosis increases wall shear stress also increases. The wall shear stress in the stenotic region, $\tau_{w}$ rapidly increases from its approached value at $z=0$ to its peak value in the upstream of the first stenosis throat at $z / \mathrm{L}_{0}=$ $1 / 6$, it then decreases steeply in the downstream of the first throat to its magnitude at the critical height $\left(0.75 \delta / R_{0}\right)$ of the stenosis at $z / \mathrm{L}_{0}=1 / 2$. The flow characteristic, $\tau_{w}$ further increases steeply in the upstream of the second stenosis throat and attains its peak magnitude (same as at the first throat of the stenosis) at the second throat of the stenosis at $z / \mathrm{L}_{0}=5 / 6$, it then decreases rapidly to the same magnitude as its approached value (at $z=0$ ) at the end point of the constriction profile at $z / \mathrm{L}_{0}=1$ (Figure-5, 6). The wall shear stress distributions show a close mirror image of the outline of the stenosis.

The wall shear stress distribution, $\tau_{\mathrm{w}}$ increases for some fixed value of $\delta / \mathrm{R}_{0}$ and $\mathrm{k}$ in stenotic region at any axial distance, $z / \mathrm{L}_{0}$, (figure-5).

Shear stress affects endothelial cell (Glagov et al. 1988). The balloon helps to widen blood vessels and improve blood flow. To inflate and deflate the balloon several times to push the blockage aside to restore blood flow in blood vessel. The wall shear stress distribution, $\tau_{\mathrm{w}}$ decreases with increasing value of $z_{\mathrm{d}}$ for some fixed value of $\delta / R_{0}$ and $\mathrm{k}$ in stenotic region at any axial distance, $z / \mathrm{L}_{0}$, (figure-5).

For the analysis of blood flow characteristics through stenosed artery, wall shear stress near the throat of the stenosis deserves special attention. It has significant role in the development of arterial diseases. The peak of the wall shear stress is believed to cause severe damage to arterial lumen. The variation of shearing stress at stenosis throat with stenosis size, $\delta / R_{0}$ is shown in Figure- 8 and 9. Figure- 8 illustrate that the shear stress at stenosis throat, $\tau_{s}$, increases with stenosis size, $\delta / \mathrm{R}_{0}$, with increasing $\mathrm{k}$, for fixed $\mathrm{z}_{\mathrm{d}}$, and balloon height, $\delta_{0} / \mathrm{R}_{0}$. 


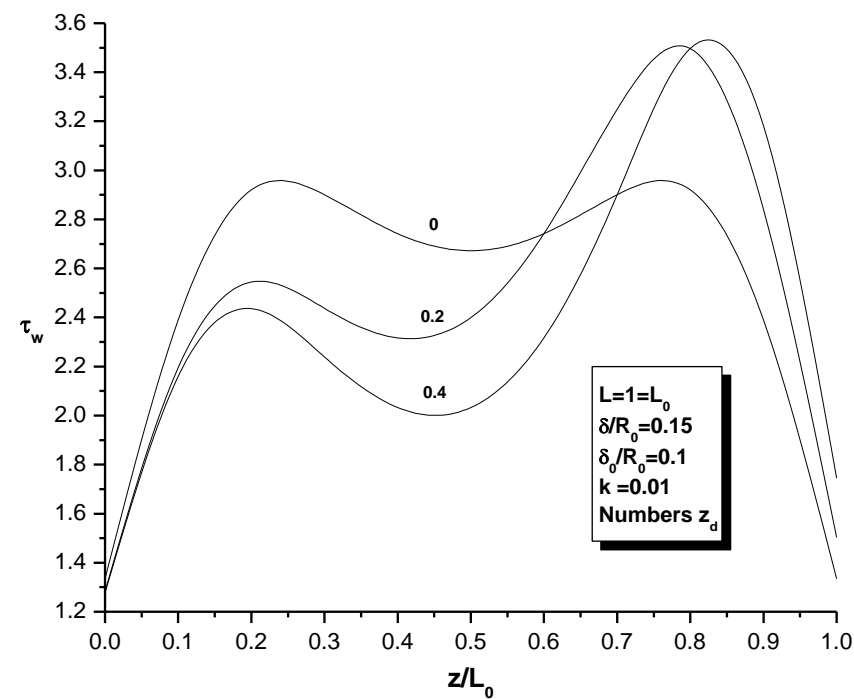

Figure 6: Wall shear stress distribution, $\tau_{\mathrm{w}}$ in stenotic region for different axial displacement of balloon, $\mathbf{z}_{\mathrm{d}}$.

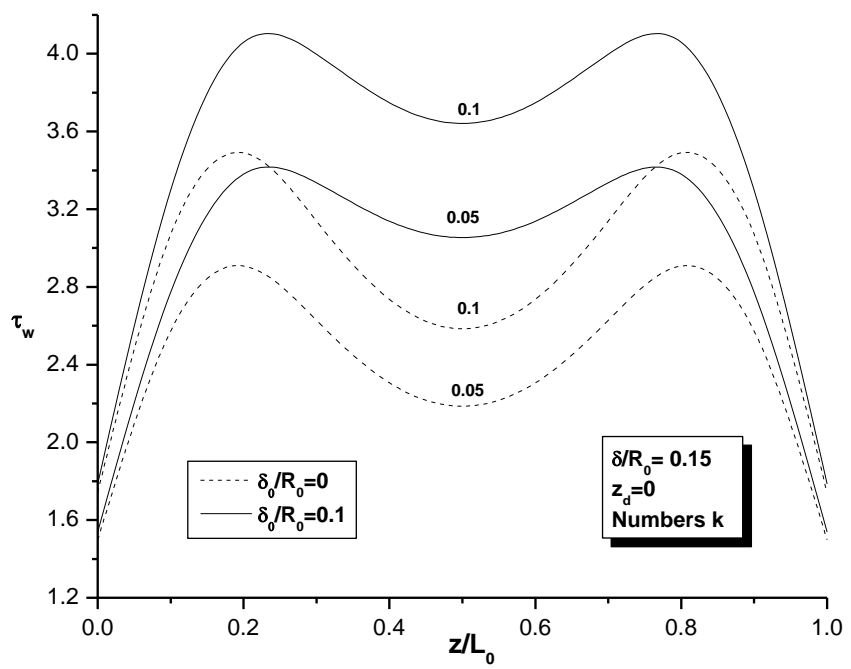

Figure 7: Wall shear stress distribution, $\tau_{\mathrm{w}}$ in stenotic region for different catheter size, $\mathbf{k}$.

Figure-9 illustrate that shear stress at stenosis throat, $\tau_{s}$, increases with stenosis height for given catheter size. For $\mathrm{k}=0.01$, the shear stress at stenosis throat, $\tau_{s}$, increases due to balloon of height, $\delta_{0} / \mathrm{R}_{0}=0.1,0.15,0.20$ is about $45.77 \%, 72.92 \%$ and $107.39 \%$ approximately over that of stenosed catheterized artery for stenosis height, $\delta / R_{0}$ $=0.10$. 


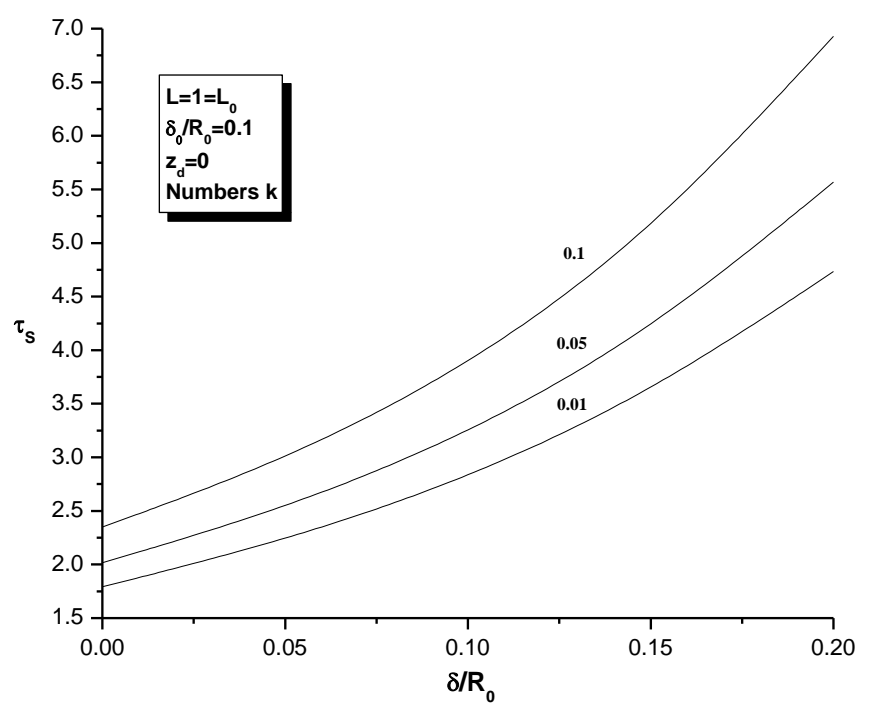

Figure 8: Shear stress at stenosis throat, $\tau_{\mathrm{s}}$ versus stenosis height, $\delta / \mathbf{R}_{0}$ for different catheter size, $k$.

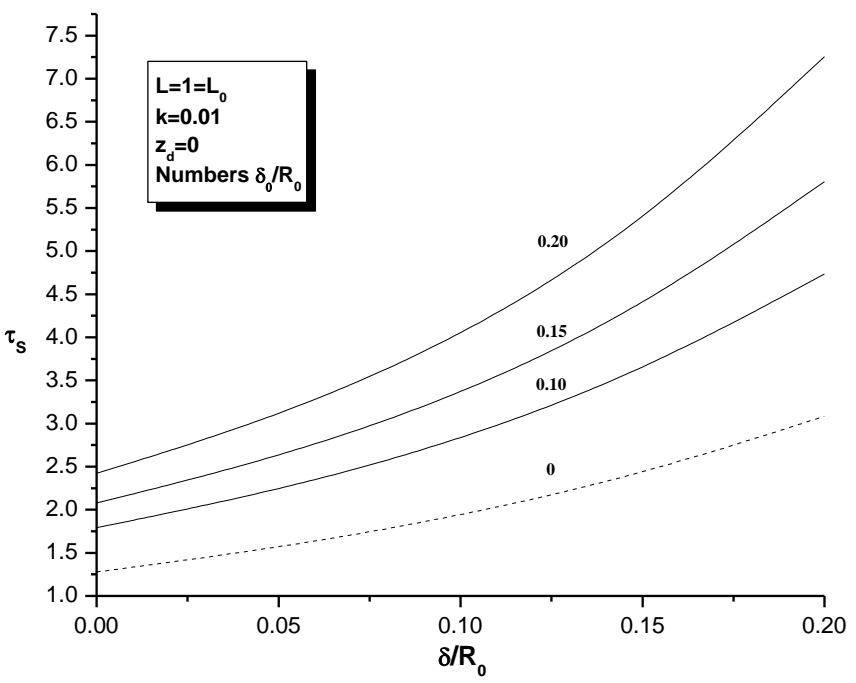

Figure 9: Shear stress at stenosis throat, $\tau_{s}$ with stenosis height, $\delta / \mathbf{R}_{0}$ for different height of balloon, $\delta_{0} / \mathbf{R}_{0}$.

\section{Conclusion:-}

The effect on flow characteristics due to stenosis size, maximum height attained by the balloon, the radius of catheter which keeps balloon in position and axial displacement of balloon studied. The conditions $\delta / R_{0}<<1$, very early stages of vessel constriction and $\delta_{0} / R_{0}<1$, balloon height, limits the usefulness of present study which allows the use of fully developed flow equations and leads to a local poiseuille-like flow. Balloon based catheter technique system that applies mechanical pressure to blood vessel walls has dramatically advanced the standard of care for patients with vascular disease. The insertion of balloon with catheter into artery leads to considerable increase in the magnitudes of fluid characteristics. Balloon inflation opens blocked arteries i.e. treatment of stenosis and restores normal blood flow. Balloon based catheter technique system has emerged as the standard tool of care for coronary arterial disease. The present analysis may be useful for medical purpose. 


\section{References:-}

1. Akbar NS, Nadeem S (2014). Simulation of peristaltic flow of chime in small intestine for couple stress fluid. Meccanica 49: 325-334.

2. Anderson HV, Roubin GS, Leimgruber PP, Cox WR, Douglas JS Jr, King SB and Gruentzig AR (1986). Measurement of transtenotic pressure gradient during percutaneous transluminal coronary angioplasty, Circulation 73: 1223-1230.

3. Caro CG, Pedley TJ, Schroter RC and Seed WA (1978). The Mechanics of the Circulation. Oxford Medical, New York.

4. Dash RK, Jayaraman G and Mehta KN (1996). Estimation of Increased Flow Resistance in a Narrow Catheterized Artery-A Theoretical Model. Journal of Biomechanics, Vol. 29(7): 917-930.

5. Gabe IT (1972). Pressure measurement In experimental physiology, In cardiovascular Fluid Dynamics. Academic Press, London 11-49.

6. Glagov S, Zarins C, Giddens DP, Ku DN (1988). Hemodynamics atherosclerosis: insights perspectives gained from studies of human arteries. Arch. Pathol. Lab. Med. 112: 1018-1031.

7. Gunj P, Abben R, Friedman, Granic JD, Barry WH, Levin DC (1985). Usefulness of transstenotic coronary pressure gradient measurements during diagnostic catheterization. Am. J. Cardiol. 55: 910-914.

8. Hazarika GC, Sarmah A (2014). Blood flow through a stenosed artery with the effect of transverse magnetic field using a non-Newtonian model. Int. J. of Computer Applications 10 (1): 5-8.

9. Ledesma JM, Riahi DN, Roy R (2013). Two-phase flow in a catheterized artery with atherosclerosis. J. of Theoretical and Applied Mechanics 51(2): 409-418.

10. McMahon TA, Clark C, Murty VS and Shapiro AH (1971). Intra aortic balloon experiments in a lumpedelement hydraulic model of the circulation. J. Biomechanics 4: 335-350.

11. Medhavi, A, Srivastav, R. K., Ahmad Q. S. and Srivastava, V. P. (2012). Two-phase arterial blood flow through a composite stenosis. e-jst, 7(4), pp. 83-94.

12. Mishra BK, Panda TC (2005). Non-Newtonian model of blood flow through an arterial stenosis. Acta Ciencia Indica. 31, M(2): 341-348.

13. Perktold PK, Karner G, Leuprecht A, Hofer M (1999). Influence of non-Newtonian flow behavior on local hemodynamics. J.of Appl. Math. and Mech. 79(S1): 187-190.

14. Ponalagusamy R and Tamil Selvi R (2011). Blood flow through stenosed arteries: new formula for computing peripheral plasma layer thickness, Int. J. Bio-Sci. \& Bio-Tech., 3(1): 27-37.

15. Riahi DN and Roy R (2012). Unsteady blood flow in an artery with an overlapping stenosis. Internatinal J. of Applied Mechanics 4,(2), 16pages.

16. Srivastav RK (2014). Mathematical Model of Blood Flow Through A Composite Stenosis In Catheterized Artery With Permeable Wall. Applications and Applied Mathematics, Vol. 9, Issue 1, 58-74.

17. Srivastav RK., and Srivastava VP (2014a). On Two-Fluid Blood Flow Through Stenosed Artery with Permeable Wall. Applied Bionics and Biomechanics, Vol.11 Issue 1-2, 39-45.

18. Srivastav RK and Agnihotri AK (2014b). Non-newtonian power law blood fluid flow through a bell shaped stenosis in artery. Journal of Multidisciplinary Scientific Research 2(4): 15-19.

19. Srivastav RK. (2015). Two-Layered Model of Blood Flow Through Arterial Catheterization with nonSymmetric Constriction. J. of Computation in Biosciences and Engineering, Vol. 2, Issue 2, 1-8.

20. Srivastav RK.(2017). Blood flow analysis through a bell shaped stenosed artery. Lambert Academic Publishing.

21. Srivastava VP and Srivastava R (2009). Particulate suspension blood flow through a narrow catheterized artery. Computers and Mathematics with Applications, 58(2): 227-238.

22. Srivastava VP, Rastogi R and Vishnoi R (2010). A two-layered suspension blood flow through an overlapping stenosis. Computers and Mathematics with Applications 60: 432-441.

23. Venkatesan J, Sankar DS, Hemalata K and Yatim Y (2013), Mathematical analysis of Casson fluid model for blood rheology in stenosed narrow arteries. Journal of Applied Mathematics, Article ID 583809, 11 pages.

24. Wilson RF, Johnson MR, Marcus ML, Aylward PEG, Skorton D, Collins S, White CW (1988). The effect of coronary angioplastyon coronary flow reserve. Circulation 77: 873-885.

25. Yilmaz, F and Gundogdu MY (2008). A critical review on blood flow in large arteries; relevance to blood rheology, viscosity models and physiologic conditions. Korea Aust. Rheol. J. 20: 197-211.

26. Young DF and Tsai FY (1973). Flow characteristics in model of arterial stenosis - steady flow. Journal of Biomechanics 6: 395-410. 